\section{STRETCHERS FOR THE WOUNDED IN THE TRENCHES.}

By G. H. CoLT, F.R.C.S. ENG.,

CAPTAIN, R.A.M.C. (T.F.) ; ASSISTANT SURGFON, ROYAL INFIRMARY, ABERDEEN.

ON August 15th, 1915, I received a letter from Captain D'Arcy Power, R.A.M.C. (S.R.), at the front, in which he says :-

We are in most urgent need of a stretcher for use in the trenches. Although we have all for months past been trying to devise something, all our efforts have failed so far. The communication trenches are very long in certain parts of the line. They are 27 inches wide at the level of the hip and 29 inches wide at the level of the neck. They have no traverses, but they bend about in rather sharp curves and are 6 feet deep. The fire trenches are 19 inches wide at the level of the hip and 25 inches wide at the level of the neck, and are 9 feet deep. They are formed with traverses of 6 feet at intervals of 20 feet, and the chief difficulty is in getting round these-i.e., in turning the corners. The diagonal width across the corner of such a fire trench is 29 inches at the level of the hip and 32 inches at the level of the neck. The regulation stretcher fails utterly, but in a communication trench where there are no traverses, but only bends, the bearers may hold the stretchers at arms' length over their heads. The fire trenches are too deep for this, even if it were safe. My dressing station was situated 800 yards behind the front-line fire trench, and with our present lack of suitable stretchers it took anything from $1 \frac{1}{1}$ to $2 \frac{1}{2}$ hours to bring a wounded man 800 yards back this distance. Then if it was an urgent case and it was daylight he had to be man-handled down another 800 yards of trench to a village where a motor ambulance was stationed. If the case could wait till dark the ambulance was able to run up to the dressing station and thus save this second 800 yards of carrying, but even in the dark the car was able to get up no further as the road was all shell holes.

Now, after a year of war, and especially after the publication of Captain G. K. Aubrey's article ${ }^{1} \mathrm{draw}^{\text {. }}$ ing attention to the need of stretchers for the wounded in the trenches, it is unfortunate that more experimental work on the subject has not been published. Such work could only be carried out with difficulty if done on active service, whereas many surgeons at home might be able to design a pattern of stretcher that would prove efficient. Early and quick transport is probably of equal importance as, if not of greater importance than, the application of a field dressing. There is nothing difficult about the manufacture of Aubrey's stretcher. It consists essentially of two poles each 4 feet long. Each is provided with a hinged leg, which when let down enables the stretcher to be balanced while the bearers take a rest. The width of the stretcher when fully expanded is $20 \frac{1}{2}$ inches. There are no traverses. The patient sits with his back and head against the chest of the back bearer and his legs hang down.

From the measurements of the fire trenches given in the letter the maximum length diagonally across the convex angle of the corner measured at right angles to the line joining the convex and concave angles is only 4 feet, and this is reduced to 3 feet at a distance of 9 inches from the convex corner. Aubrey's stretcher could not possibly pass round a corner in so small a trench in the ordinary way. Since there are no transverse props in this pattern of stretcher, by compressing it laterally and tilting it sideways or upwards it might be made to pass at the risk of tipping the patient out or of causing him pain. He may be secured, as Aubrey suggests, by a band across the chest. This stretcher

1 The LanCeT, Dec. 26th, 1914, p. 1488. was made on the spot, it proved of much service, and several were soon in use in the brigade; but Aubrey had no doubt that it could be improved, and hoped that suggestions to enhance its value would be made by others. In a letter which followed his article, signed "W.J. M. E.," the suggestion was made to adapt a wheel-barrow for the purpose of negotiating the sharp turns of the spurs thrown out to protect the trench from enfilading fire. "Shallow troughs could be fixed on either side of the wheel, and in these the patient's legs could be laid. Where the bearer company was insufficient to deal with large numbers of the wounded, it would be possible to manage a case with only one bearer." "W "W.J.M. E." also suggested that when mud and water prevented this method of transport a chair carried on the tilt with lashed poles and side ropes to prevent an insensible patient from falling out could be used.

The measurements of the trenches given above are less than those shown in the sketches in "Field Service Pocket Book, 1913," and no doubt exigencies of service, greater safety, and the nature of the soil demand different measurements in different localities. To be obliged to place men in a trench so narrow that even two unwounded persons could only pass with difficulty and to be unable to provide a quick and efficient means of moving them along it when wounded is unsatisfactory. New trenches. also may in some respects be more difficult to traverse than those in which the corners have been worn away. It should be noted that even a small rounding off of the convex angle at any corner makes a relatively large difference in the ease with which a stretcher can negotiate it and adds very little to the risk from enfilade fire. Baying out the concave angle has much less effect as regards ease of morement.

\section{Methods Tried.}

The officers and men had tried :-

1. A single pole stretcher with the canvas slung below it by cords like an Indian "doolie" or "dandy." The pole had a joint in the middle, and failure had resulted as no satisfactory joint could be evolved. This was one of the best arrangements tried. The failure of the Indian dandy to negotiate the corners and slopes in mountain warfare is well known.

2. Rogers's stretcher. 'The poles are 3 feet 6 inches long. Bands for the shoulders are attached to the upper end of the upright portion of the canvas which is thus held up by the front bearer, against whose back the patient leans. As in Aubrey's stretcher the patient sits with his legs hanging down. The length of the seat is 23 inches and the width 18 inches. As a matter of experience it was found that most of the weight came on the front bearer. The stretcher could not be lowered to the ground with a badly wounded man in it, and so the bearers could get no real rest. An unconscious patient was apt to roll off, as the hands of the bearers were fully occupied and there was no room for a third man to hold him on.

3. A chair tied on to two poles and carried with the seat tilted slightly. This arrangement answered well in some cases and was readily improvised. A disadvantage of it that was not mentioned is that when used for a patient with a fractured femur the seat is too short to act as a splint and its front edge may act injuriously so as to cause further displace. ment of the fragments. 
4. A blanket or ground-sheet carried by the corners. This is in common use, but is often difficult and tiring to manage. For unconscious patients liable to suffocate, for "gassed" patients, and for cases of fracture of the lower limbs this method is most unsuitable. The same objections apply to any stretcher of the hammock type in which no prop is provided to keep the bearers the same distance apart.

It is apparent from the foregoing that the problem is one of some difficulty. Such questions as lightness, the possibility of setting the stretcher down for the bearers to rest, loading and lifting the stretcher, passing men and boxes in the narrow spaces, and above all causing as little pain and injury to the patient as possible, have to be considered. At present the bearers soon get knocked up. The advantage of Aubrey's stretcher over Rogers's is that it has two folding legs which can be let down, and the stretcher is then balanced while the bearers rest. Soft ground must result in difficulty in this respect. Shoulder bands also may be used for the suspension. I am told that any rigid stretcher which has no traverse is tiring for the bearers to manage. In both these types the patient is apt to roll off, and it is a question whether the sitting-up position is a good one for any unconscious patient. In both cases the patient's legs hang down. There is no great disadvantage in that provided they do not knock against uneven ground and are not kicked by the adjacent bearer. If there is a fracture of the leg bones extension will be made by the weight of the limb and the boot. A bayonet or other simple short splint could be lashed to the leg below the knee. The advantage of the position is that the carrying length of the patient is comparatively small. In the trials carried out by us it was found that it was a disadvantage to provide an extension piece to the canvas for supporting the legs and feet because of the varying length of leg in different patients. Such supports are uncomfortable even in the absence of injury, may lead to further injury if a fracture is present, and if made adjustable are apt to be too complicated. A simple stirrup is one of the best of such supports and can be readily improvised by tying on a sling of bandage in the required place. From the illustrations ${ }^{3}$ given of a further development of this type of stretcher it would appear that the vertical supporting poles could readily be used for splinting the outer sides of the patient's legs. The ends of such props and the ends of any upward projecting pole or back rest catch in the sides of a trench when the stretcher is tilted sideways.

\section{The "Fowler Position."}

Now it seems to me that the Fowler position, or a near approach to it, would be a better one than the sitting-up position. In the case of an unconscious patient there is not the same degree of risk of his falling out and he is more readily controlled if he is restless. For thoracic and abdominal cases, more especially cases of com. mencing peritonitis, the position is one of the best, if not the best, that could be chosen. For a case of fractured femur it is not by any means bad, because the support lies evenly from the buttocks to the knees, but if the fracture were near the knee-joint it is at present a matter of trial to see how the position answers. For a case of injury to the leg, especially a fracture, as

3 THE LANCET, Oct. 23rd, 1915, p. 928. already mentioned, the only disadvantage is the risk of the injured limb being knocked by obstacles or by the adjacent bearer. For cases of severe collapse or shock the position is not the best theoretically, but the speed with which the vascular system adjusts itself to the maintenance of blood pressure, even in severe cases, is often remarkable, and the cause of the collapse may be peritonitis. The Fowler position, especially if maintained by a rigid system, can be quickly reversed so that the head is low and the pelvis high. Some years ago Colonel H. M. W. Gray had constructed for him a rigid tray with canvas floor, after an American pattern, for the purpose of moving patients in the Fowler position from an operation table back to bed in a nursing home where there were one or two awkward corners on the stairs. The patient could by this means be tipped up nearly vertically, and in this way the contrivance readily negotiated the corners. The great advantage of the Fowler position for present purposes is that the carrying length of the patient is seldom greater than 4 feet, and is usually less than this.

\section{The Flexible Method.}

Attempts to utilise the position may be made in three ways-viz., the flexible, the semi-rigid, and the rigid. In the first a strip of canvas 5 feet loug is taken, and at one end it is fastened to a trans. verse knee-piece which is suitably curved so as to partially splint the back of each knee and maintain a distance of some 4 inches or more between them.

FIG. 1.

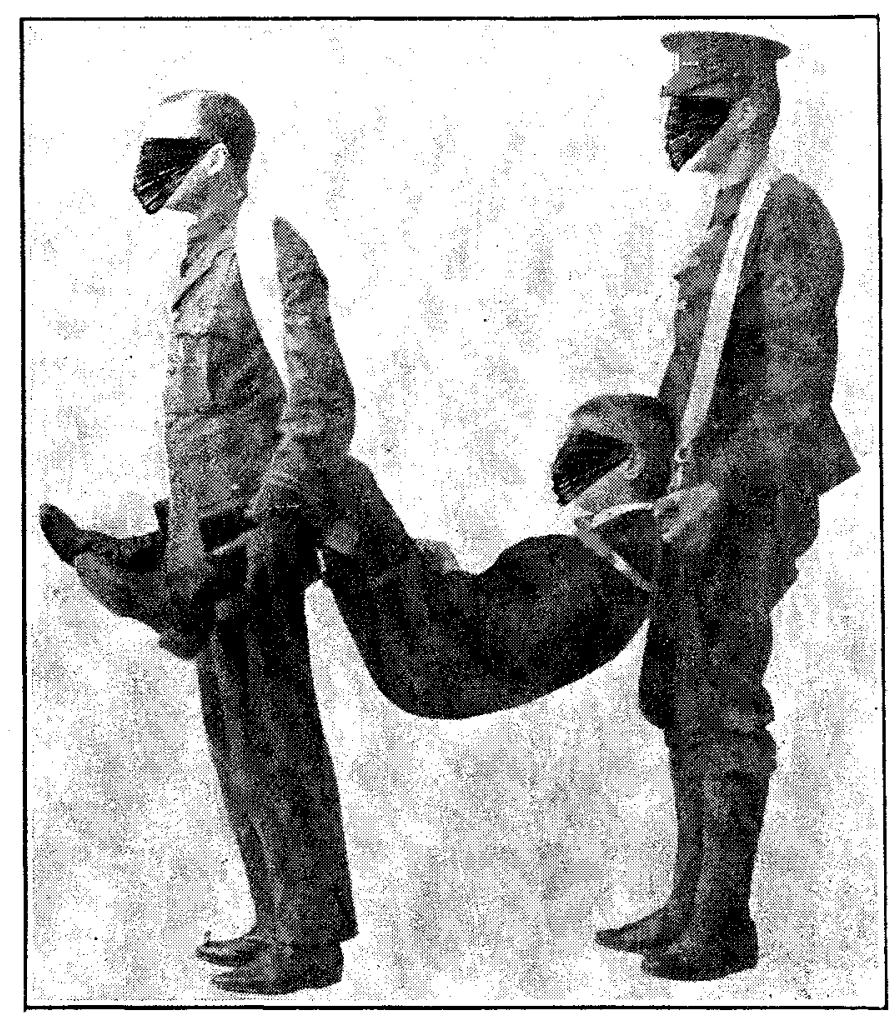

The "Fowler position": flexible method.

At the other end a rounded head-frame is attached and continued down to the shoulders, where a crosspiece, suitably curved so as to be comfortable, is fixed about 12 inches from the top of the headpiece. The shoulder-piece and head-frame are in one piece, so that the traction applied to the top of the shoulder-piece, together with the weight of the patient acting along its lower border, tend to keep the head-piece upright. The length of the finished sling is 4 feet 6 inches, and 
the width of the knee-piece and shoulderpiece and the canvas stretched between them is 16 inches. This is ample for almost any patient, and less will do, especially at the knee. The edges of the canvas are turned over two side ropes which join up the corresponding ends of the knee- and shoulder-pieces. These ropes are slightly shorter than the length of the canvas so as to give it a transverse bay like the sag of a much used deckchair or a hammock. The side ropes can be omitted with certain kinds of canvas. To the ends of the shoulder-and knee-pieces webbing shoulder bands are attached by hasps and rings. Fig. 1 gives an idea of the arrangement, and it is apparent that the method is really an improved form of the blanket stretcher. It is certainly more comfortable both for the patient and the bearers than a simple "fore-and-aft" carry. Suitable bands can be added to restrain the patient, the chief situations for these being just below the axillæ and just above the knees. The height of the lowest part of the patient from the ground is about 1 foot 10 inches. No provision has been made in this arrangement for keeping the bearers the same distance apart during transit. The lack of this and the sideways spread of the feet with insufficient room for his legs are the chief objections to this method of carrying a patient. The weight is $5 \mathrm{lb}$.

\section{The Semi-rigid Method.}

In the second or semi-rigid method the part of the stretcher in which the patient reclines is of the type described above. It may conveniently be susFIG. 2.

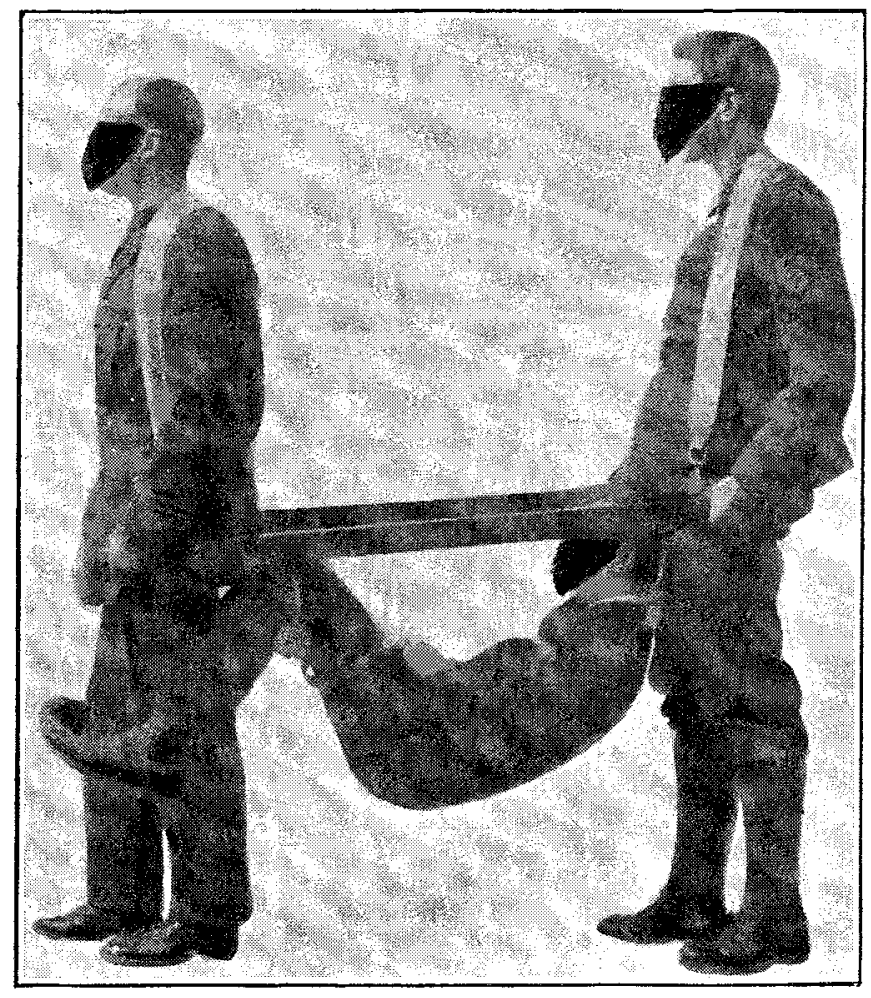

The "Fon ler yosition" : semi-rigid method.

pended in two ways. The first is by means of two side poles each 4 feet long, as illustrated in Fig. 2 . The poles are attached to the shoulder- and kneepieces by hasps and swivel rings which can easily be released. Webbing slings may be added for the shoulders of the bearers. A hinged prop may be provided for each pole as in Aubrey's stretcher, so that the apparatus may be balanced on hard ground, and allow the bearers to rest. It seems to me that for simplicity it is better to omit the supporting props and to rely on other relief in this respect. The objection to these props in any short-poled stretcher is that when dependent they catch in the walls of the trench and the feet of the adjacent bearer directly the stretcher is tilted sideways. If the ground is soft they are apt to sink into it. Four small shields could be added near the outer sides of the ends of the handles of any short-poled stretcher so as to prevent the knuckles of the bearers from being scraped by the walls of the trench. This would appear to be a much needed im provement. From the figure it will be seen that the only rigid part of the sling between the poles is the head frame, and the poles may be approximated to this extent when turning a corner. The outside width of the two poles is then only 11 inches. This allows the stretcher to negotiate a right-angled corner in a trench 28 inches wide, but the bearers require practice for this, the patient's feet are apt to catch in the sides of the trench and more weight is thrown on the back than on the front bearer. This stretcher might be regarded as a modified form of Aubrey's, with the substitution of the Fowler for the sitting-up position, with a reduction in width of $4 \frac{1}{2}$ inches, and with the addition of traverses. It folds up for packing. The weight of the apparatus complete is $11 \mathrm{lb}$. In any stretcher of this type it is difficult to reduce the efficient length of the poles below 4 feet. This leaves barely sufficient room for the patient's legs, even if the front bearer were to manage to walk quite evenly. The lowest part of the patient is only 10 inches off the ground.

In the second form of stretcher of the semi-rigid type the suspension is from a jointed pole, as shown in Fig. 3. The pole proper is of larch, the yokes of sarch, a wood of the willow type, tough and light. This avoids any risk of the yoke splitting across the ends, but if the yokes were made of bent wood, as would probably be the case in manufacture, there would be no necessity to use sarch. The suspension is by ropes with hasp and eye attachment. The pole is divided into two parts which engage at the central joint. This is conveniently effected by a simple nut and bolt allowing movement in a horizontal plane. Now it is found that dixectly eren a slight displacement occurs at the joint, forces come into play which cause a couple to act the moment of which about the joint tends to increase the displacement, the condition being one of unstable equilibrium. Unless some kind of stop were pro vided disaster would follow, the pole collapsing com pletely. In the course of the experiments one of the journeymen carpenters solved this part of the problem after a few trials. It is by far the most important part of the matter. He provided a lever and handle situated above the pole. This addition results in complete control of the joint, and is in itself a very beautiful piece of mechanics. The front end of the lever is fixed to the front part of the pole, the fulcrum is at the joint, and the handle moves free. The back bearer by moving the handle determines the exact degree of bend at the joint and restores the same as required. By suitably pressing on the handle in an upward direction he is able to prevent any tendency that he feels may exist for the joint to collapse. When the pole is straight the handle of the lever can be locked to the back part by a hasp, so that the pole is held rigid and the hands of the back bearer are freed. For certain special cases, such as the use of the stretcher on spiral staircases, a side extension bar may be affixed so as 
to engage the handle by stops and so enable the mud. The weight is more evenly distributed two parts of the pole to be locked at any required between the bearers, but the front bearer is angle. This bar is not illustrated. To utilise the purposely given more than the back one. This theoretical advantages of the lever fully the method of suspension is a great improvement on forward end should be attached at a point distant the last and the strain on the bearers is considerfrom the joint equal to one-sixth part of the length ably less. The apparatus, in fact, becomes a of the pole and the handle should be one-third of manageable thing. The over-all length is 5 feet this distance from the joint; but in actual practice and the outside width of the front or larger of both these measurements may be departed from the two body girlles 15 inches. The total weight without much loss of efficiency, and as regards the is $23 \mathrm{lb}$. There is no doubt that this could handle end of the lever with some degree of gain be reduced to $18 \mathrm{lb}$. and possibly less with because a shorter handle is less likely to scrape safety to the patient. The lowest part of against the side of the trench. It is to be noted the patient is about 16 inches off the ground. that in turning a corner the handle projects towards The stretcher can be loaded and will pass round the concave angle of the trench while the stretcher right-angled corners in a trench 18 inches wide. negotiates the convex angle. One great advantage During his transit in such a narrow trench the of this type of stretcher is that other men in the patient scrapes the corner. If conscious and able trench are able with care to step around and pass it. to use his arms he can assist by pushing himself In an early pattern of this type, since discarded, the away from it. In a wider trench this would not yokes were borne on the shoulders of the bearers. be necessary. The increased ease of movement is The great disadvan. tages of this system were the difficulty of raising the yokes on to the shoulders of the bearers and the excessive strain thrown on the back bearer. He had to resist the tendency to deforma. tion of the pole, and in this position this might be very hard work indeed. Thefront bearer was subjected to pressure on the two shoulders alternately, according to the direction of turning. The fact, however, remains as a result of trials, that this type of stretcher with the pole $6 \mathrm{ft}$. 3 in. long over all, and the yokes $12 \frac{1}{2}$ in. wide outside measure, could just be made to pass round the corners in a trench 28 in. wide and one in which the convex corners are sharply

FIG. 3.

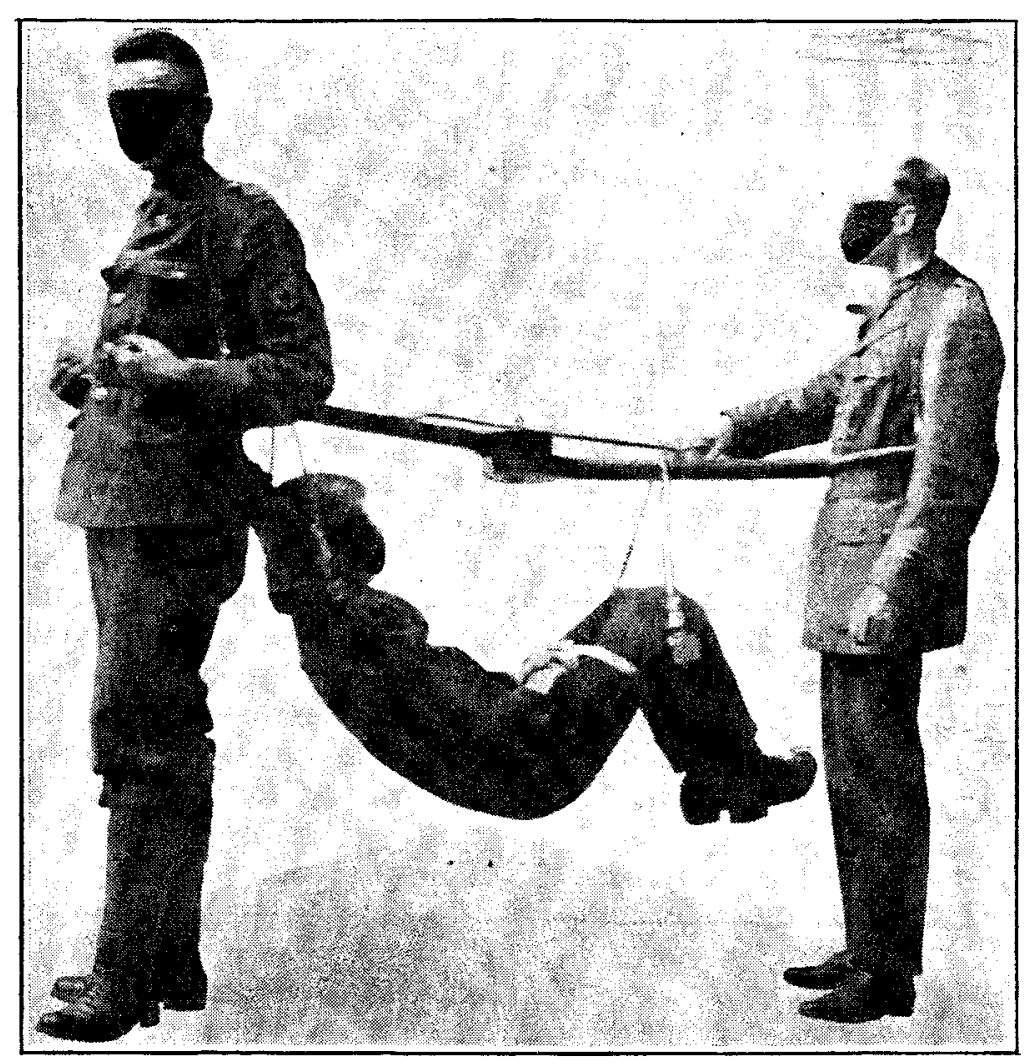

The "Fowler position": suspension from a jointed pole. marked and there is just room for the patient's legs. Throw. ing more weight on the front than on the back bearer compensates the latter for his exertion in working the lever and enables him to keep a good look-out. A disadvan. tage of carrying the patient backwards is that the back bearer has no means of controlling him if he is unconscrous. The assistance of a third man is required in hasping up the bar to the shoulder-straps of the bearers and in releasing them, but otherwise two bearers can manage alone. In a winding trench 20 inches wide having no sharp corners but merely sharp bends there is very little difficulty in walking quickly with a patient. cut. As already mentioned, if these corners are slung as here described. In a cornered trench rounded off slightly the ease of passing them is 22 inches wide there is not much difficulty, and largely increased.

In order to try to overcome the great strain on the bearers and the other disadvantages of the earlier pattern, the suspension shown in Fig. 3 was designed. In this the yokes of the pole are suspended from the shoulders of the bearers so as to be level with the lower part of their chests, which they fit fairly closely. They may also be held in the hands. At times, notably on a straight stretch, the bearers trust the weight to the shoulder slings entirely. The lever in this case is worked by pulling from above it instead of by pushing it from below, and the back bearer may have two hands free for this purpose. The distance of the patient from the ground being less than when the yokes are carried on the shoulders the consequences for all three are not likely to be so serious should any accident happen, but the patient is more likely to become soiled by in one 24 inches wide the bearers can walk quickly with ease. No short-poled stretcher yet designed can be made to negotiate a corner with comfort to the patient and ease to the bearers in a trench 26 inches wide.

The question arises as to how the patient is to be placed in a stretcher of this type. No doubt much will depend on circumstances. Probably the patient will be carried to the nearest spot where the trench widens out, and then lifted into the sling. In other cases it may be more convenient, especially if the bottom of the trench is dry and there is room to move a little, to unhasp and spread the canvas on the floor of the trench and lift the patient lengthwise, or lift or roll him sideways on to it. In doing this the important point to remember is to place the knee-piece directly under the knees, the rest is self-adjusting as regards length. The head-end of the canvas is placed in the direction. 
of transit. Then, if necessary, the restraining bands will be adjusted, the bearers will take up position and stoop down, holding the yokes while a third man fits the hasps to the eyelets of the canvas. The back bearer will lock the lever.

FIG. 4.

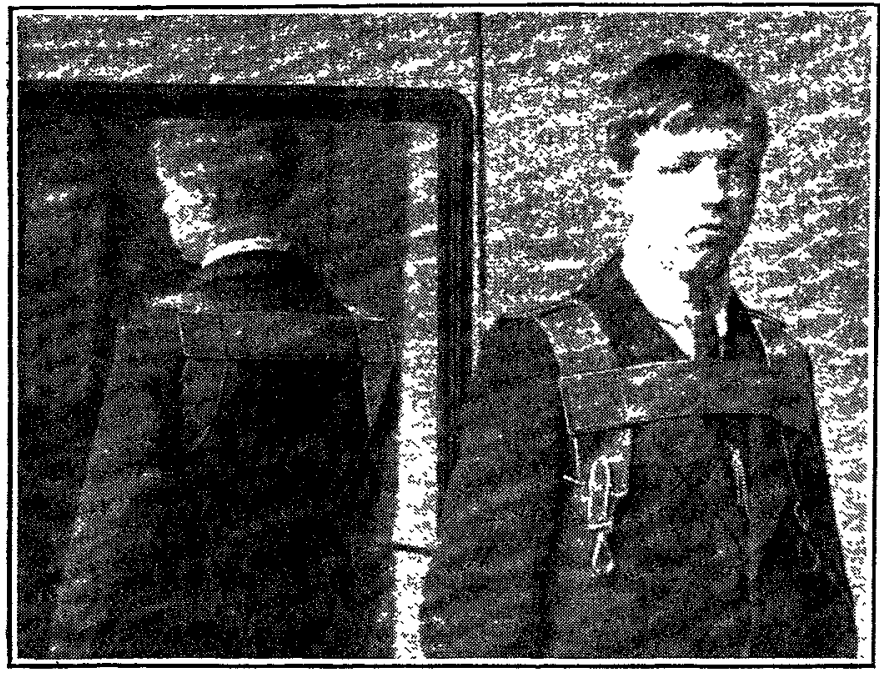

True shoulder suspension.

The stretcher will then be lifted and hasped on to the shoulder-slings. In certain cases the patient's head will be turned on one side and bandaged or strapped to the headpiece. In other cases, one or both of his feet will be placed on the chest or shoulders of the back bearer and a long splint applied from the hip. The back bearer will unlock the lever and the party move off.

The bearers could obtain rest either by working in relay stages or by providing at intervals poles with a fork or crutch at the top in which the bearing pole could be balanced and the canvas kept off the ground. If there should happen to be a convenient dug-out or other ledge, the sling can be swung sideways and set down on it. The soldiers would always offer a hand for temporary relief. With this type of suspension the bearers cannot set down a heavy patient unaided on to the ground on which they are walking, and even with a light patient there is a strain on the knees when attempting to do this. On the return journey other bearers could easily carry a 10 stone weight of food and ammunition for distribution along the fire trenches.

The regulation method of socalled shoulder

suspension is by a band of webbing as shown in Figs. 1 and 2 . In actual practice, especially during lifting and_setting down, this becomes raised up on FIG. 5.

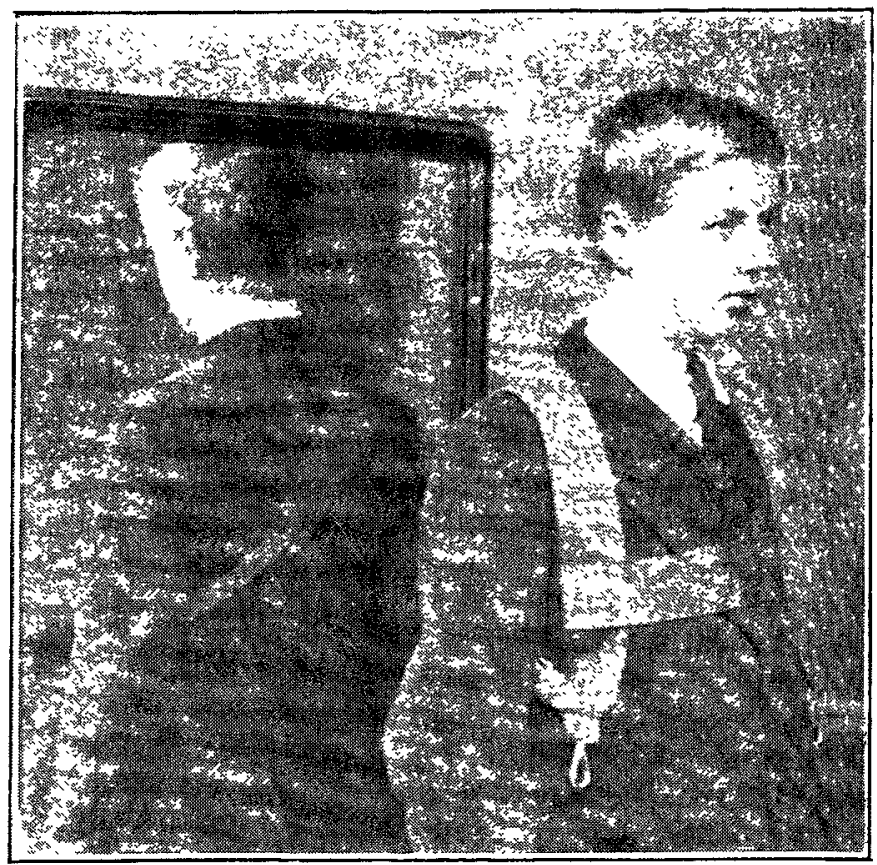

Improved form of the same.

to the bearer's neck and the strain is much greater than it should be, partly, no doubt, owing to actual constriction and partly to the muscular effort compressing the veins of the neck and leading to retention of waste products in the muscles. The true shoulder suspension illustrated in Fig. 4 is a great improvement, bringing as it does the weight direct on the shoulders and removing it entirely from the neck. In the short suspension required for the jointed-pole stretcher a difficulty is to obtain arm-hole room, and in the case of the actual collar illustrated the bearer

FIG. 6.

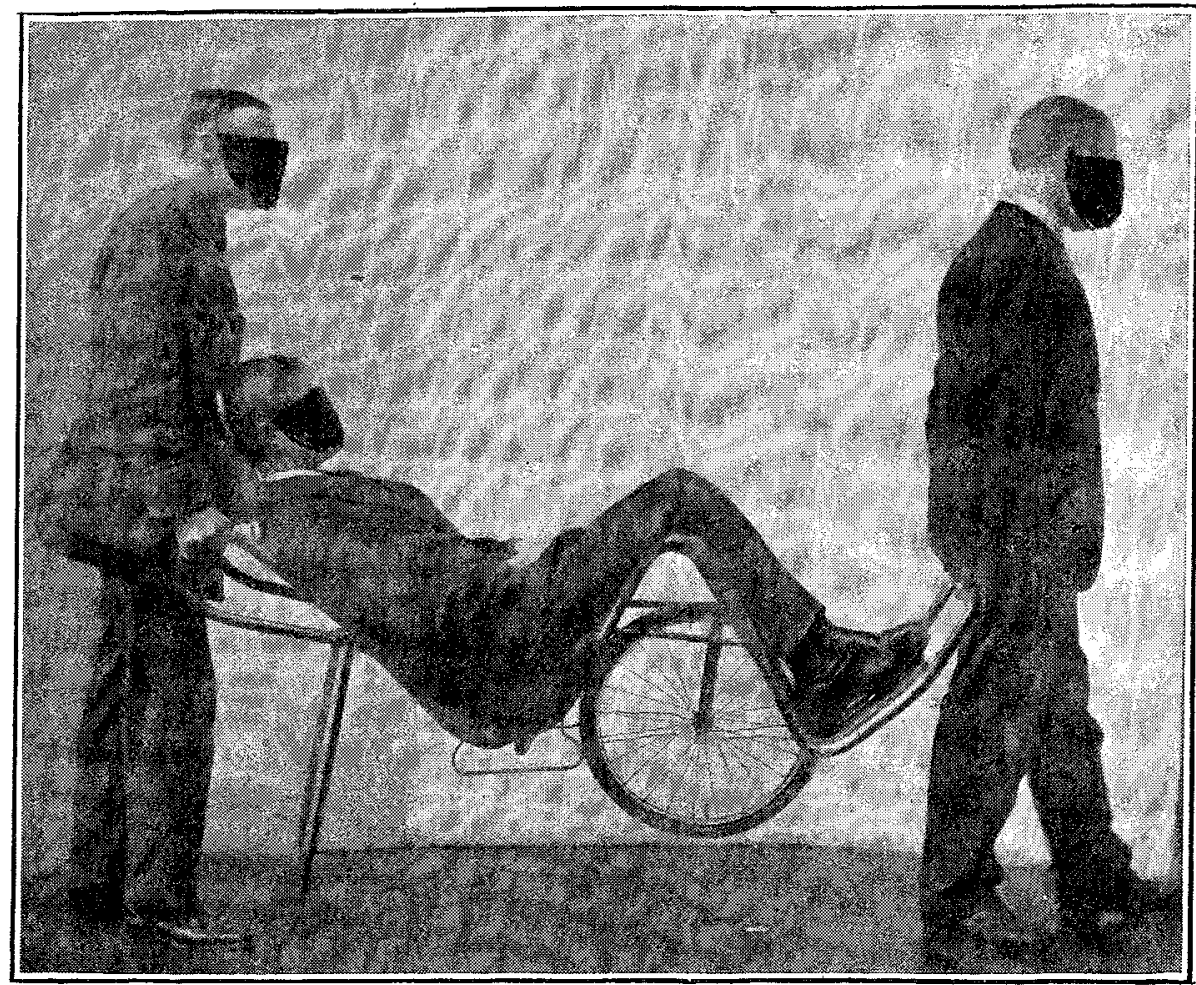

The "Fowler position": the rigid method. has some little difficulty in adjusting the collar himself. These objections can be got over by omitting the horizontal back band, lengthen. ing the webbing, crossing the two ends over the back and carry. ing them round to join the front pieces under the opposite axillæ, as shown in Fig. 5. This pattern also is more easily constructed. In a longer type of webbing suspen. sion these diff. culties do not arise, and it would be a humane thing if. some.such 
shoulder collar as described were substituted for the regulation band now in use. The bearers would not get knocked up nearly so much; in fact, the total gain considered over the whole front after an action would be considerable. Without this improvement the jointed-pole stretcher would not have come to fruition, whereas at the present time it would appear to be the only stretcher that will efficiently accomplish its purpose in fire trenches 18 inches to 26 inches wide.

In the stretchers described the sling in which the patient is placed is distinctly comfortable to recline in, and the feeling is one of even support for the whole of the body with the exception of the lower part of the legs.

\section{The Rigid Method.}

In the third or rigid method of using the Fowler position the suggestion already referred to, to employ a modified wheelbarrow, has been carried out. Fig. 6 shows one of the experimental pieces of apparatus, which in this instance has been made of cycle tubing and sheet metal. It is $4 \mathrm{ft}$. $6 \mathrm{in}$. long, $15 \mathrm{in}$. wide, and weighs without the under-carriage $25 \mathrm{lb}$. When carried it will just negotiate a right-angled corner in a trench 29 inches wide, and when wheeled it will pass in one 26 inches wide. By reason of its shape the tray portion is a complete natural splint for the head, neck, body, and lower limbs. It may be carried tilted up, horizontally, or tilted down, and could be swung nearly vertically over the side of a ship or down the shaft of a mine with scarcely any disturbance of a strapped-in patient. The under-carriage for the wheel or wheels can be made detachable, and if conditions for wheeling were suitable it could be left on the return journey at the end of the communication trench ready to be utilised for running the next case along, but if preferred it could be hooked on at the back. In order to lessen the load on the back bearer when wheeling the stretcher the axle should be set far back, nearly under the patient's centre of gravity, but unless the height of the axle off the ground is increased this setting back decreases the efficiency in turning a corner. Setting the axle well forwards increases this efficiency by reducing the turning length, but it would appear to be unlikely that this length between perpendiculars can be reduced below $3 \mathrm{ft} .2 \mathrm{in}$, in which case such a stretcher could just be made to scrape round a corner in a trench 22 inches wide. In some trenches illustrated in the weekly papers there is a false bottom of planks under which the water lies. In these trenches the use of this pattern of stretcher might be found to be a quick and easy means of moving a patient. It is also probable that when perfected it would answer for general transport work, but not necessarily for lying down cases when deposited in casualty clearing stations or ambulance vans. The manufactured article would be a simple tray of metal stamped in one piece and rimmed up with light tubing. After removing the under-carriage such stretchers could be packed up like saucers one on the top of the other, and so be made easily portable for use in quantity. In civil work, and perhaps in some forms of military work, four wheels would be used with this form of stretcher. Owing to the difficulties of obtaining materials and labour, the further experiments with this type of stretcher are likely to take a considerable time. I therefore thought it best to publish this article now instead of waiting for their completion so that others may be able to assist.

The photographs from which the illustrations have been made were taken by Messrs. G. and W. Morgan, of Aberdeen, who have spared neither pains nor experience to illustrate the details. In carrying out the designs and trials, the help and suggestion of numerous friends have been invaluable, and I take this opportunity of offering them my grateful thanks. There is little doubt that others will already have thought of and tried some of the general designs, especially the more simple ones, indicated in this article, and in this respect $I$ particularly do not wish to claim priority. The matter seemed to me to be an important one, and as such to be deserving of attention. I hope that the general outline given of this particular part of the subject-viz., the utilisation of the Fowler position for carrying patients in stretcher work-may help towards a practical solution of the problem.

\section{CANADA.}

(From OUR OWN CORRESPONDENT.)

\section{Vital Statistics in Canada.}

ONTARIO has probably the best system of registration of any of the provinces of Canada, as regards births, marriages, and deaths. It has been registering for over 45 years, but it is claimed that one in every five births escapes registration. Canada is said to be very far behind other British Overseas Dominions in regard to the compilation of vital statistics; and if the above statement is correctand there seems to be no doubt of it as it comes from a responsible source-then the other provinces of Canada which are not up to the standard of Ontario in health matters must have a very nominal vital statistics department.

\section{An Important Legal Decision.}

An action was recently brought against a Canadian general practitioner. The plaintiff was a woman who consulted her physician about a lump in her breast. The physician, at the time of the examination, detected a lump in the other breast as well. A surgeon was consulted and the first breast was removed. At the operation, and while the patient was still under the anæsthetic, the physician told the surgeon there was a lump in the other breast and that he had secured the patient's consent to the removal of both lumps. The double operation was done. Some time later trouble arose in the arm corresponding to the second operation. An action was brought against the surgeon for assault, the patient claiming that he had not had her consent to the double operation. The case came to trial, and there was a conflict of evidence between the patient and her physician, the latter claiming that the patient had given to him her consent for the removal of the second breast. Having heard a considerable amount of evidence in the case, the justice held that a surgeon is justified in performing an operation additional to the original one where the case demands that more be done than was at first considered proper. A surgeon might, in fact, be open to blame if he failed to perform a second operation where he found such necessary for the cure of the patient. 